\title{
perifèria
}

Número 7, Diciembre 2007

www.periferia.name

\section{Transformación de instituciones religiosas tradicionales en el Alto Atlas de Marrakech (Marruecos) y su impacto en los ecosistemas sub- alpinos. Caso del sistema pastoral del agdal}

\section{Resumen}

Pablo Dominguez - UAB/EHESS/LPED ${ }^{1}$

En mi presentación subrayaré la importancia de las instituciones religiosas tradicionales del territorio de montaña del Yagur en la conservación de los actuales ecosistemas sub-alpinos. Las instituciones religiosas tradicionales apoyan al sistema agdal, que consiste en la prohibición de acceder a los pastos de alta montaña durante tres ó cuatro meses en primavera y que, según numerosos autores, resulta beneficiosa ecológicamente. La hipótesis principal que subyace es que para entender el concepto del agdal y sus impactos en la protección del medio subalpino, los sistemas bio-ecológico, tecnológico, jurídico y económico sobre el que reposa el agdal no puede ser amputado de su dimensión simbólica y religiosa, siempre en perpetua transformación. La pregunta concreta que intentaré responder en mi presentación es si la creencia en los santos del Alto Atlas, además de ser un elemento de construcción de la cosmología local, es también un elemento relevante de la economía y ecología del Yagur. Las observaciones de campo que describiré a continuación, sugieren que el cambio acaecido en las instituciones religiosas tradicionales de los santos del Atlas es causa y efecto indisociable de la manera en que son gestionados estos pastos, y que dicho sistema simbólico es parte relevante de la economía y ecología locales.

Palabras clave: etnoecología, cosmología, sustentatibilidad, Alto Altlas, pastores.

\begin{abstract}
In this paper, I will underline the importance of the traditional religious institutions of the mountain territory of the Yagur in terms of conservation of present subalpine ecosystems. The traditional religious institutions support the agdal system, which consists on the prohibition to accede to the high mountain pastures during three or four months in spring and which seems to bring ecological benefits. The main hypothesis is that to understand the concept of the agdal and its impacts on the protection of the sub-alpine environment, the bio-ecological, technical, juridical and economical systems, on which the agdal is based, cannot be separated from their symbolic and religious dimension, always in transformation. The question we ask ourselves is: do the believes on the saints of the High Atlas, beyond an element of local cosmological construction, are also a relevant element of the economy and the ecology of the Yagour? The fieldwork observations that I will describe below, suggest that the changes in the traditional religious institutions of the saints of the Atlas, are cause and effect of the way in which these pastures are managed, and that this symbolic system is a relevant part of local economy and ecology.
\end{abstract}

Keywords: ethnoecology, cosmology, sustaintability, High Atlas, sheperds.

\footnotetext{
${ }^{1}$ Enviar correspondencia a: Pablo Domínguez dominquezggpp@gmail.com
} 


\section{perifèria}

Número 7, Diciembre 2007

www.periferia.name

\section{I ntroducción}

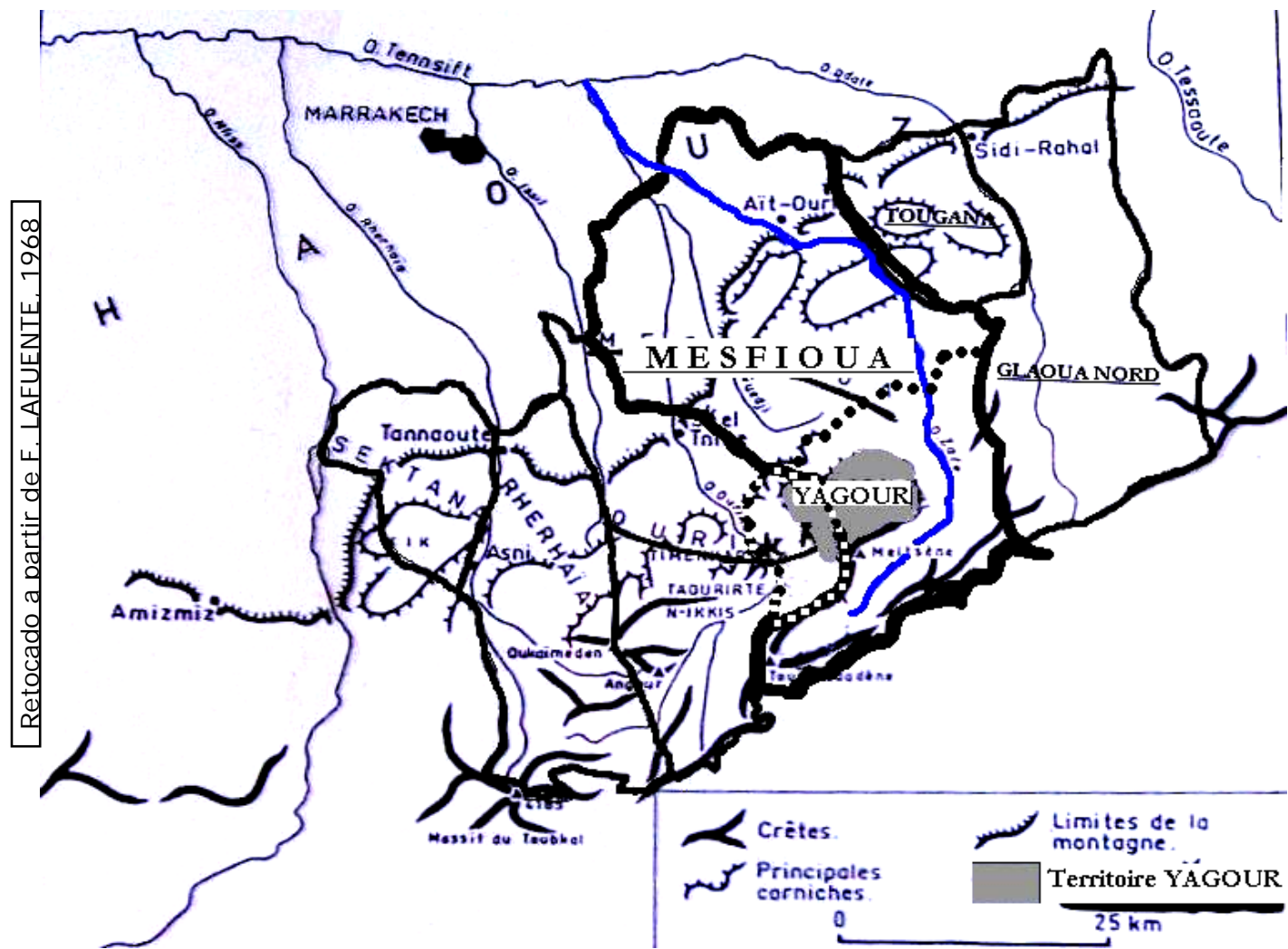

Mapa 1: Situación de la zona de estudio (Yagur)

Primero de todo tendré que definir claramente dos conceptos, el Yagur que es el territorio donde se ha desarrollado el estudio y el Agdal, que es el sistema que gestiona dicho territorio.

La zona de estudio del Yagur, es un territorio de unos $70 \mathrm{Km}^{2}$ entre 1.900 y 3.600 metros de altitud que se sitúa a unos $40 \mathrm{Km}$ de Marrakech a vuelo de pájaro (Mapa 1). El Yagur es utilizado directamente por unas 1.000 familias o unas 7.000 personas de cinco fracciones tribales (Mapa 4, p. 9), pero dicho territorio también atañe alrededor de 25.000 personas de la tribu Mesioua, ya que su apertura (el territorio pastoral del Yagur se cierra de marzo a julio...) determina también la apertura de otros pastizales de altitud cercanos debido al gran tamaño del Yagur. 


\section{perifèria}

Número 7, Diciembre 2007

\section{www. periferia.name}

Este territorio conoce una ocupación humana intensa a partir de la fundición de las nieves (febrero-marzo) con un desdoblamiento del hábitat en los apriscos de altitud, que se hace especialmente intenso en verano.

En cuanto al concepto del agdal, éste tiene una etimología compleja, su raíz se encuentra por todo el norte de África, desde Túnez al sur de Argelia o Marruecos, y tiene significados muy variados como por ejemplo un hermoso bosque, una pequeña pradera, un territorio tribal de más de $100 \mathrm{Km}^{2}$ o incluso "dejar crecer los cabellos". En términos estrictamente agronómicos y para el caso del Yagur, el agdal corresponde a la prohibición establecida por la asamblea tribal, de acceder a los pastos colectivos, teóricamente del 28 de marzo al 23 de julio. En otras palabras, el agdal representa el consenso entre las gentes que tienen acceso a este recurso. Los usuarios del agdal, deben determinar de antemano y con el común acuerdo de todos, las fechas de apertura y cierre del Yagur. Ésta práctica tiene efectos particularmente benéficos sobre el recubrimiento vegetal y la biodiversidad local (Foto 1 y Foto 2) (Kerautret 2005: 150, Al Ifriqui 2005: 35, Alaoui Haroni, Al Ifriqui \& Simonneaux 2005, Alaoui Haroni \& Al ifriqui 2006, Ballini C., Bertaudière-Montès, Deschamps-Cottin, Lempérière \& Montès 2005: 15). 


\section{perifèria}

Número 7, Diciembre 2007

\section{www. periferia.name}

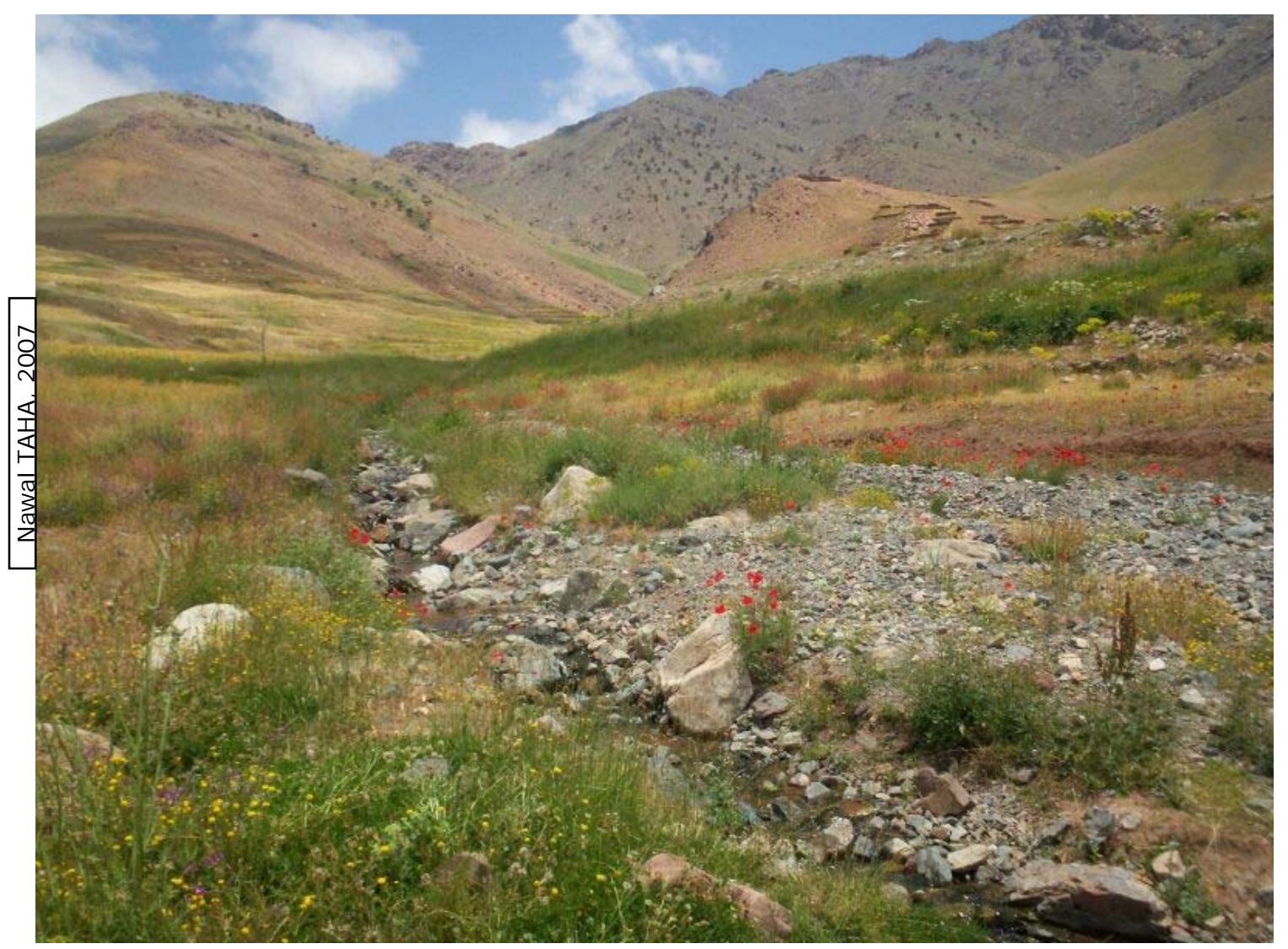

Foto 1: Espacio pastoral de altitud con la hierba muy crecida después de 3 meses de prohibición del pastoreo 


\section{perifèria}

Número 7, Diciembre 2007

\section{www.periferia.name}

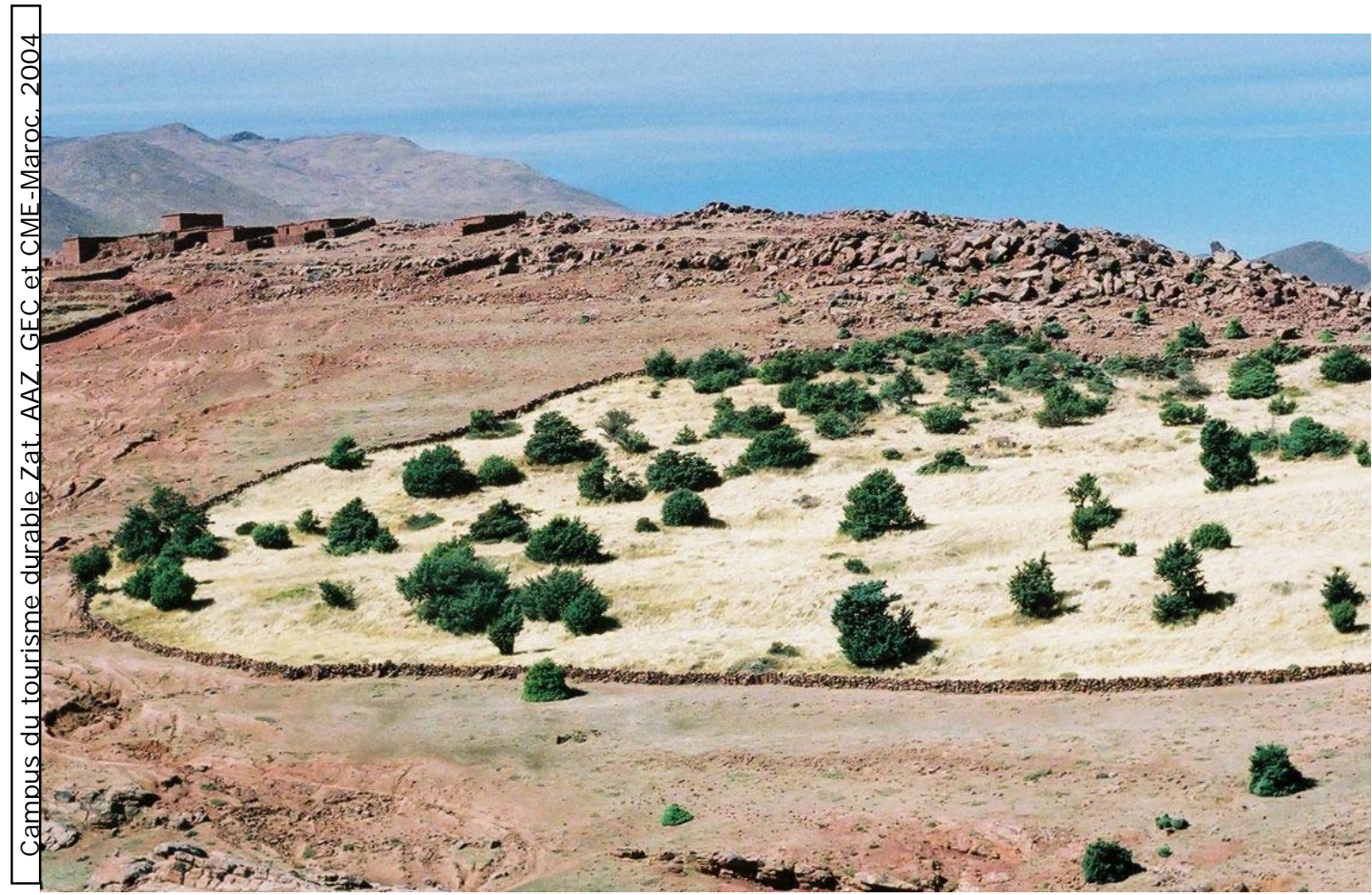

Foto 2: Cementerio berebere en agdal y el Yagur al fondo, con un resultado ecológico evidente ( $p o o l /$ reservorio de biodiversidad y punto de difusión de semillas)

De hecho, como ocurre a lo largo de todo el Alto Atlas, alrededor del Yagur se encuentran diversos tipos de agdales (es decir, la prohibición de acceder temporalmente o permanentemente a un recurso natural determinado). Así pues, en el Yagur, además de los agdales pastorales, encontramos agdales forestales, frutales, cerealeros, etc., incluso cementerios protegidos por el agdal denominados tagdalt, es decir, pequeño agdal (Foto 2). Esto, por el efecto de mosaico de ecosistemas en el conjunto del territorio debido a una utilización especializada y diferenciada de la tierra, implica claramente un impacto sobre el plano ecológico de pool o reservorio de biodiversidad, que sirve también como punto de difusión de semillas (Mapa 2). Es importante subrayar que estos espacios-agdales están protegidos del ganado y de la extracción humana, en parte, por la fuerza de las creencias y múltiples tabúes que pesan sobre estos sitios, a menudo portadores de un cierto contenido sacro. 


\section{perifèria}

Número 7, Diciembre 2007

\section{www.periferia.name}

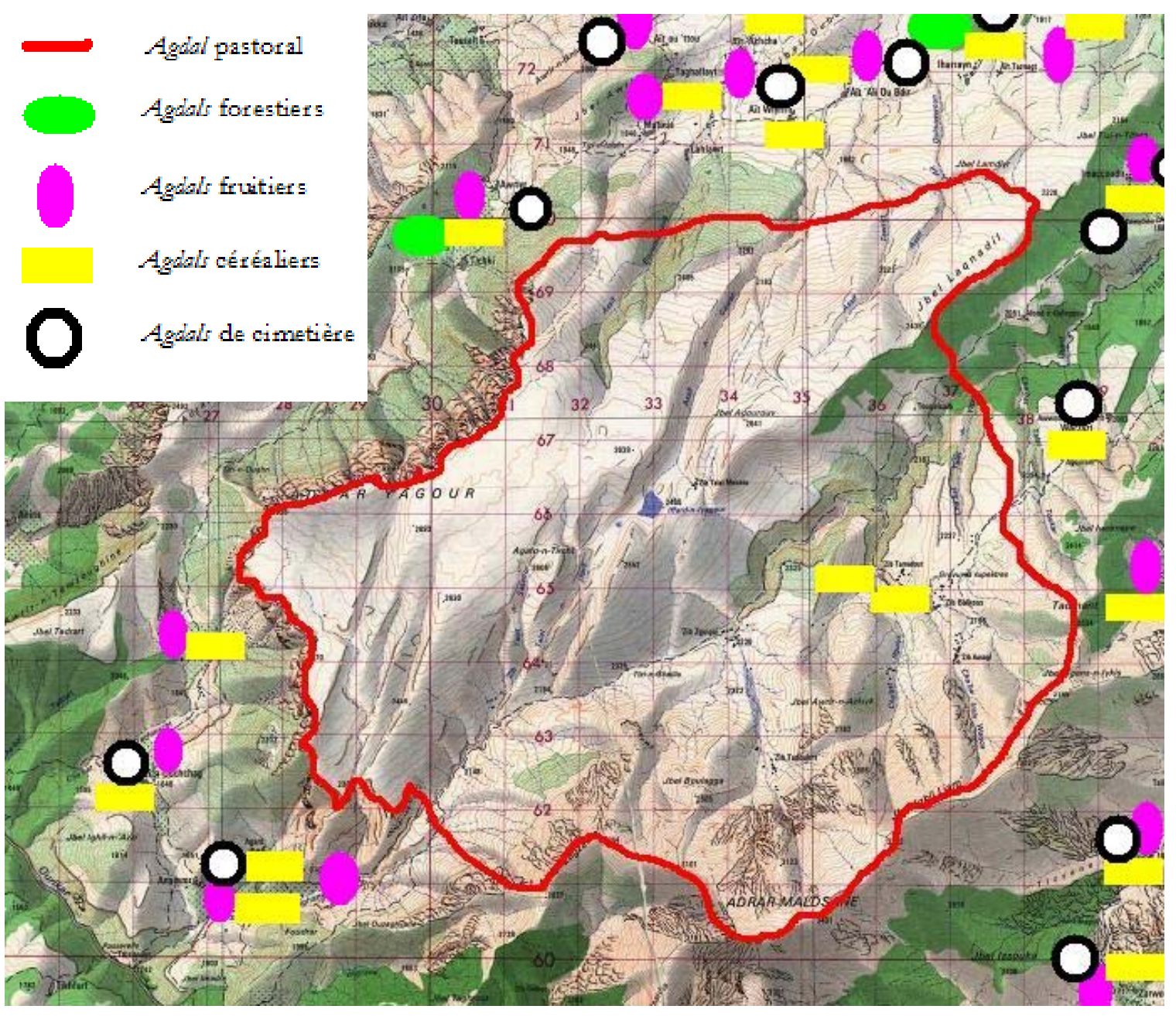

Mapa 2: Mapa esquemático de los diferentes agdales del Yagur y su entorno.

Después de haber subrayado brevemente el rol del agdal en materia de protección de los recursos naturales, analizaré muy resumidamente los aspectos religiosos ligados al funcionamiento de esta institución (sacralización de las reglas, rol de santos personajes, instituciones religiosas, creencias, etc.). Más precisamente, analizaré la relación entre la institución del agdal y el Islam tal y como se practica en el Alto Atlas. 


\section{perifèria}

Número 7, Diciembre 2007

www. periferia.name

Como es el caso en numerosas otras poblaciones pastoriles de esta región, y como han mostrado numerosos autores (Mahdi 1999: 347, Rachik 1992: 175, Hammoudi 1988: 251, etc.), la religión invade una gran parte de la vida de estas poblaciones de una forma propia y particular. El consenso científico dice que las convicciones religiosas en el Gran Atlas están caracterizadas fuertemente por la hibridación entre creencias preislámicas y la doctrina musulmana (Montagne 1930, Mahdi 1999: 347, etc.). Uno de los puntos más significativos de esta religiosidad, es el intento de conciliar las fuerzas del bien y del mal a través de numerosos rituales sincréticos. Por ejemplo, uno de los ritos más significativos es el sacrificio sangriento de un animal para satisfacer a los diablos y rendir homenaje a los santos, o a un linaje santo respetado por su ciencia religiosa, sus poderes mágicos y su baraka (bendición divina musulmana). Antaño, estos rituales se hacían siempre de forma colectiva, ahora son realizados cada vez más de forma individual (Mahdi 1999: 347). En muchos pueblos, los hombres honoran colectivamente al santo o a la santa del pueblo por "dones" vegetales (por ej.: dones de grano), animales (por ej.: sacrificios de ganado, dones de mantequilla, etc.), o humanos (por ej.: cortes de pelo). En contrapartida, la creencia tradicional dice que el santo enterrado "asegura" la prosperidad y la fecundidad de la comunidad a través del/los espíritu/s o diablo/s que cuida/n su tumba y el territorio del grupo. Estos rituales refuerzan simbólicamente la cohesión de la comunidad, pero también la solidez de las estructuras agro-pastorales favoreciendo su continuidad y por lo tanto la de la institución del agdal.

Es habitual tildar estas sociedades montañesas y sus sistemas agrarios de inmovilismo. Para un ojo poco advertido, la cultura local parece eterna. Sin embargo esta economía se enfrenta continuamente a cambios, a veces profundos y rápidos. Una crisis en la religiosidad local fue detonada por la llegada de la escuela en los años 80, la emigración favorecida por la intensificación de las sequías y el desarrollo socio-económico de otras regiones de Marruecos, la continua expansión cultural del Islam del cercano oriente, etc. Dicha crisis no ha dejado de crecer junto a la llegada de jóvenes voluntarios religiosos que comenzaron a introducirse en esta región hace aproximadamente dos décadas, condenando eso que consideraban 


\section{perifèria}

Número 7, Diciembre 2007

\section{www. periferia.name}

como "prácticas paganas" y "contrarias al Islam". Por otro lado, la implantación de nuevas mezquitas en toda la región entorno al Yagur, o incluso en su interior, y el trabajo constante de los imams, parece aportar sus "frutos" en detrimento de la antigua concepción religiosa de los Berebéres (Montagne 1930).

\section{Geografía humana y posición del Yagur en la actividad pastoral}

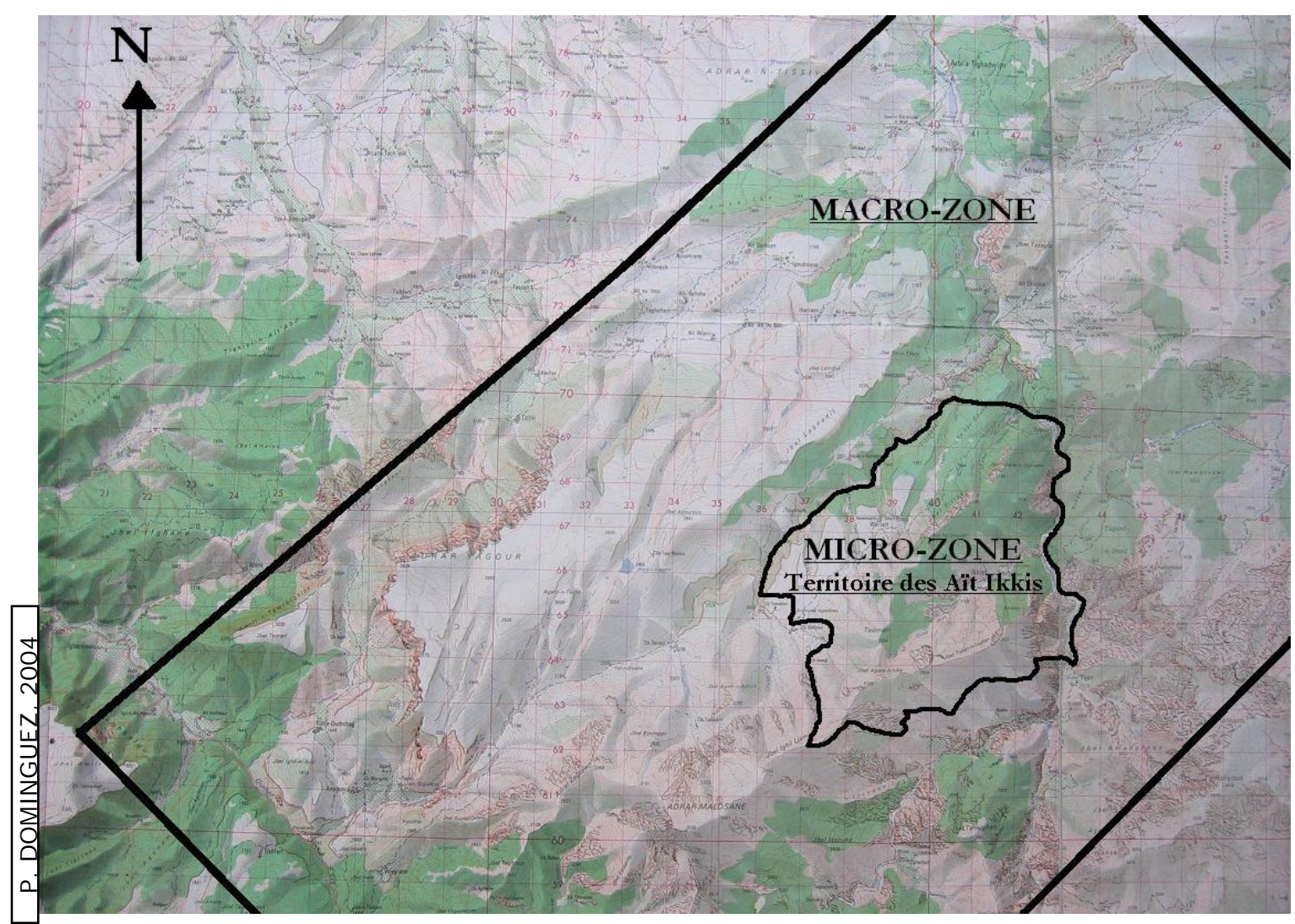

Mapa 3: Mapa de la macro-zona de estudio y la micro-zona de estudio

Mi estudio se ha desarrollado a dos niveles (Mapa 3). Por un lado he partido del estudio específico de una pequeña zona coincidente con el territorio de los Aït Ikiss, que cubre entorno a $34 \mathrm{Km}^{2}$. Por otra parte, esta micro-zona está integrada en un espacio mayor que corresponde a la parte más montañosa de la tribu Mesioua (denominación amazigh o berebere de Mesfioua). La delimitación de esta macrozona engloba al conjunto del Yagur pastoral y los territorios desde dónde parte la trashumancia. Esta unidad de entorno $400 \mathrm{Km}^{2}$, se sitúa a $40 \mathrm{Km}$ a vuelo de pájaro en dirección Sur-Este de Marrakech (Mapa 1). 


\section{perifèria}

Número 7, Diciembre 2007

\section{www. periferia. name}

De acceso aún muy difícil, el Yagur es una unidad geomorfológica de entorno a 25 $\mathrm{Km}^{2}$ a más de $2.000 \mathrm{~m}$ de altitud (altiplano formado por roca arenisca del Permotriásico), pero también, en cuanto a lo que nos interesa, un territorio pastoral más amplio de entorno a $75 \mathrm{Km}^{2}$. Todos estos espacios han sido sometidos a una orogénesis terciaria atlásica. Ésta, ha elevado las rocas graníticas más viejas del primario y precámbrico en forma de altas cadenas montañosas (entre 3.000 y $4.000 \mathrm{~m}$ de altitud) por encima de las rocas sedimentarias permo-triásicas (entre 1.000 y $3.000 \mathrm{~m}$ ) de roca arenisca desniveladas en bloques escalonados de un lado y otro de la gran falla central del Atlas (al Norte y al Sur).

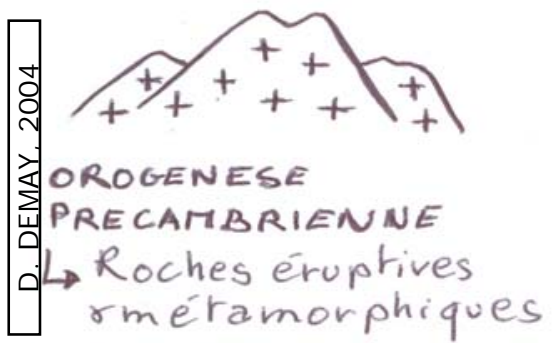

GRANITE
Norte $\rightarrow$

Iaive $\rightarrow$ IIaire

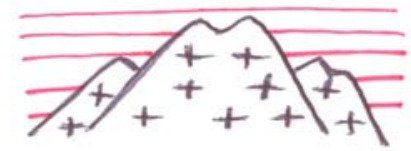

DEPOTS SEDIMENTAIRES

PERTO TRIASIQUES

GRES $\mathrm{C}$ ARGILES

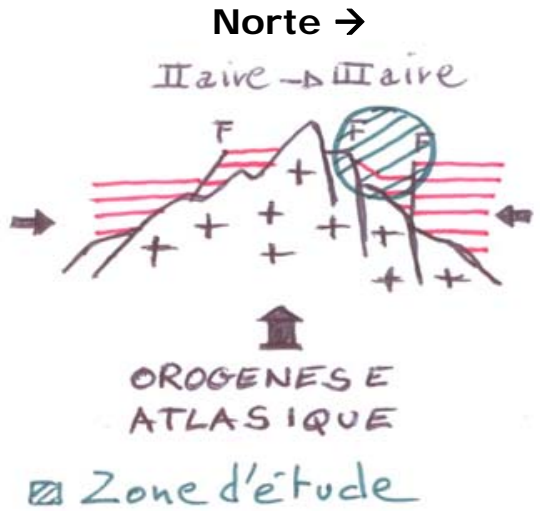

Figura 1: Corte longitudinal Sur/Norte, del Alto Atlas de Marrakech y su evolución geológica

Como otras regiones de montaña, la zona está caracterizada por la estratificación de la vegetación según un gradiente altitudinal, pero ésta está también fuertemente influenciada por las características de las rocas madre que se acaban de señalar. Diversas formaciones de tipo garriga, maquis o bosque mediterráneo perenne, ocupan las vertientes, especialmente las Norte, entre 1.000 y 2.500 metros de altitud. Entre 2.500 y 3.600 metros, dominan las plantas de alta montaña y las formaciones estepicas, especialmente las xerófitas en forma de cojinete. Estos dos grandes tipos de formación son mucho más importantes en superficie, que las praderas húmedas que ocupan biotopos muy específicos sobre el Yagur (fondos de vaguadas y pequeñas fallas, el bajo de las laderas, etc.). Gestionado en agdal (prohibición de pastorear entre marzo y julio), el Yagur es principalmente utilizado como pastos de verano aunque una gran parte de los 


\section{perifèria}

Número 7, Diciembre 2007

www. periferia. name

usuarios se queda también el otoño y también van entre febrero y marzo si no hay nieve.

Las poblaciones estudiadas guardan más o menos las marcas de la antigua organización tribal, calificada por la antropología británica como segmentaria, y está fuertemente caracterizada por un encajamiento de diferentes grupos sociales (los segmentos), organizados a la manera de un juego de muñecas rusas. Así, los Bereberes del alto Zat, es una parte que pertenecen a la tribu Mesioua, y continúan a organizarse en fracciones de tribus (hasta número de 5, Mapa 4), sub-fracciones, pueblos, sub-pueblos, linajes y familias nucleares. Estos grupos humanos organizan sus actividades y sus sistemas de gestión de los territorios (trabajos colectivos, reglas de irrigación, derechos de pastoreo, diferentes agdales vinculados por diferentes niveles "segmentarios", organización de fiestas, celebraciones religiosas, etc.) a través de las jemaa (asambleas tradicionales y consejos de buen augurio), que constituyen probablemente, el elemento más fundamental de su funcionamiento autónomo. Estas poblaciones Mesioui tienen como lengua materna el tachelhit, dialecto berebere del Sur marroquí, pero hablan también árabe la práctica totalidad de los hombres y una parte de las mujeres, por razones de trabajo o administrativas, y por la televisión o por la escuela, que empezaron a llegar a partir de los años 80. 


\section{perifèria}

Número 7, Diciembre 2007

\section{www.periferia.name}

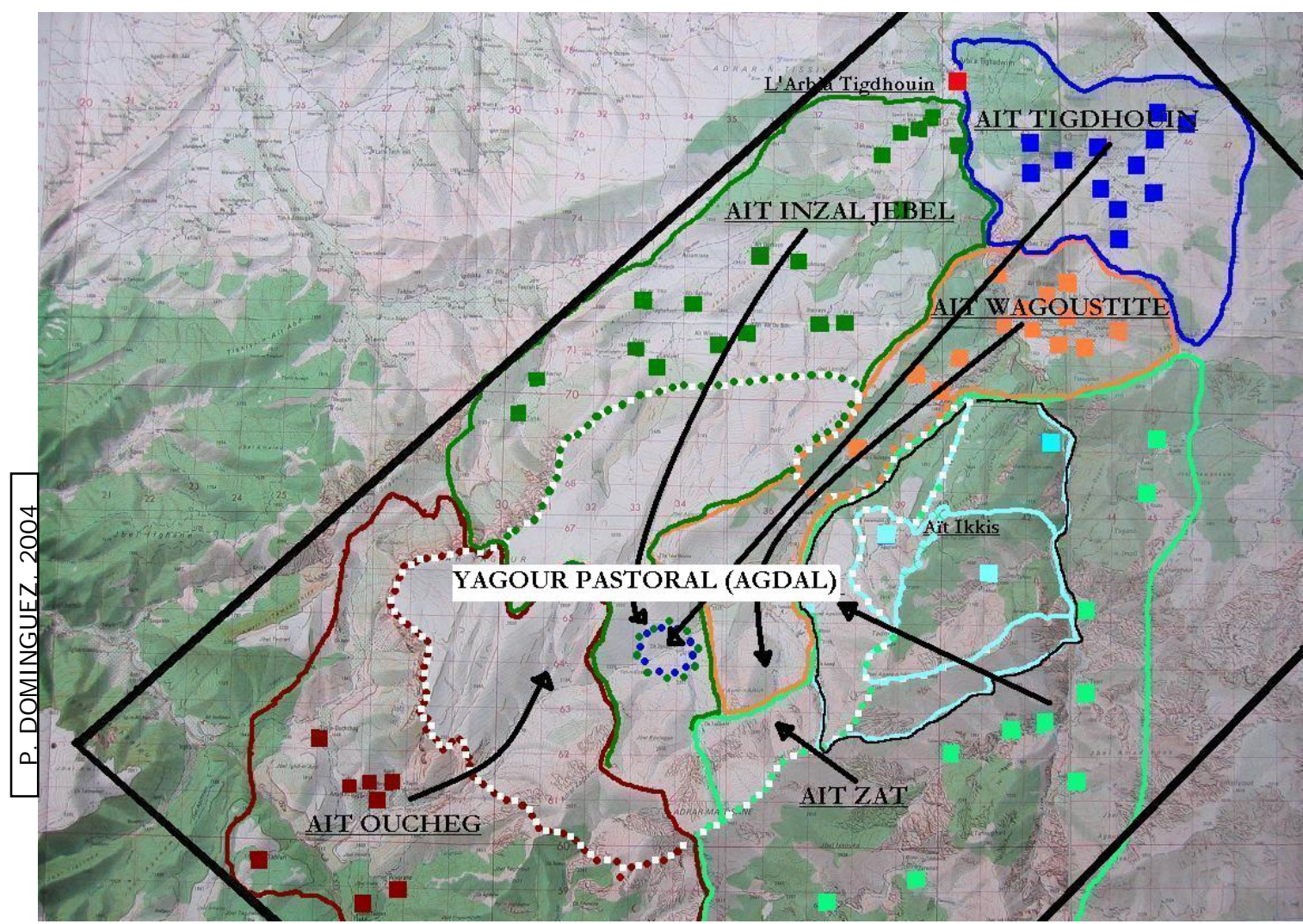

Mapa 4: Fracciones y aldeas de los altos Mesioui, y vías principales de trashumancia

El "pasto" Yagur no es más que un elemento dentro de un sistema agropastoral más vasto y complejo, que comprende los territorios de los pueblos situados en la periferia, o incluso para algunos a distancias de más de $10 \mathrm{Km}$ a pie, y que cuentan a menudo con otros sitios de pastoreo y de otros agdales. Hay 7.500 personas y casi una cincuentena de pueblos, sub-pueblos y aldeas que dependen en términos agronómicos del Yagur de forma directa, sobre un conjunto de 25.000 personas y unos 80 poblados que consituyen los Mesioui de la montaña. Varios factores se combinan para determinar los modos de conducta de los rebaños y el uso del Yagur de cada fracción tribal. Para cada grupo social, la posición relativa del Yagur en la organización pastoral es variable (distancia con respecto a la población de origen, fechas de acceso, derechos de acceso a diferentes espacios pastorales, disponibilidad de apriscos de verano, de media estación, de invierno, etc.). Tantos grupos de interés, tantos modelos de funcionamiento... 


\section{perifèria}

Número 7, Diciembre 2007

www.periferia.name

En el caso particular que he estudiado (los Aït Ikiss), el Yagur es un espacio primordial para los sistemas agropastorales. Tres elementos mayores determinan el modo local de explotación agropastoral:

- la dualidad del clima: rigor invernal y sequía estival;

- la dualidad de la topografía: valle angosto con débiles superficies agrícolas y mesetas de altitud cubiertas de gramíneas a bajo potencial de cultivo (rigor invernal especialmente limitante debido a la altitud);

- un escalonamiento de la vegetación que define etapas ecológicas complementarias en el tiempo y en el espacio (disponibilidades forrajeras y agrícolas diferentes).

Para situar a los Aït I kiss más completamente en su contexto, hace falta subrayar que el caso de los Aït Ikiss es muy particular en el seno de los usuarios del Yagur, ya que se trata de un territorio de "pre-meseta", ofreciendo algunas buenas fuentes de agua, cercanía geográfica y temperaturas suficientemente suaves, como para permitir llevar a cabo la agricultura con un cierto nivel de intensificación de sus territorios de altitud. Para algunos vecinos de los Aït Ikiss en el territorio del Yagur que se benefician también de buenas fuentes de agua y un clima todavía clemente con la agricultura, se encuentran los mismos ciclos de cultivos intensivos y de expansión de los campos de secano a proximidad de los apriscos de pastor.

\section{Análisis espacial de los Tagdalts}

Como he explicado, he realizado una investigación detallada sobre la pequeña población de los Aït Ikiss que forman parte de la fracción Aït Zat, que a su vez está integrada en los Mesioui de la montaña (ver los límites de los Aït I kiss en azul claro sobre el Mapa 4). La territorialidad de esta "población menor", está aún así muy estrechamente asociada al gran agdal inter-fracción del Yagur y sus fechas correspondientes de cierre y apertura. Sin embargo, hay otros movimientos estacionales de los rebaños que se ajustan a los tiempos de unos pequeños agdales llamados tagdalts, que se combinan con el gran agdal del Yagur, y que he querido llamar el sistema de los tagdalts. Los Aït Ikiss al Sur-Este del Yagur, son entorno a 680 habitantes y disponen de cuatro hábitats a diferentes altitudes y ecologías 


\section{perifèria}

Número 7, Diciembre 2007

\section{www.periferia.name}

(Azgour, I kiss, Warzarzt et Assagoul). Assagoul, marcado en azul en la figura aquí debajo (Figura 2), correspondería a la parte del Yagur perteneciente a los Aït I kiss.

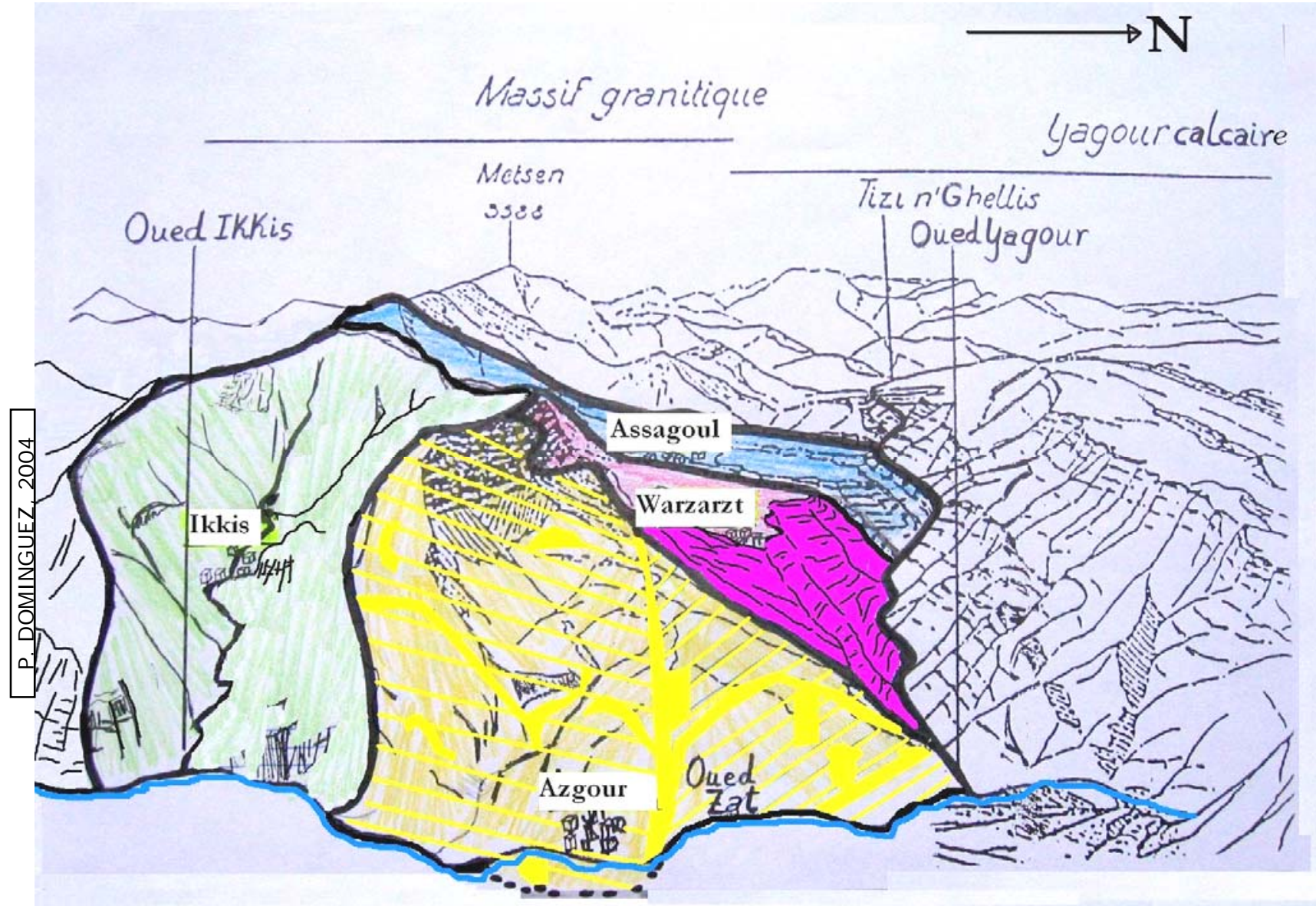

Figura 2: Territorio de los Aït I kiss y sus cuatro espacios

Esta zona de inviernos rigurosos y clima rudo, se caracteriza por un período de escasez de forraje invernal y estival. Para estos agropastores se trata pues, de practicar una ocupación razonada del territorio en el tiempo y en el espacio, con el fin de responder a las necesidades alimentarias del ganado y de asegurar las transferencias de fertilidad hacia el espacio ager. Para hacer esto, los agropastores han implantado una reglamentación de acceso a los recursos naturales de los diferentes pisos ecológicos (prohibiciones temporales de extracción de recursos). En esta parte se intentará explicar estas elecciones de prohibiciones temporales ritmando los desplazamientos del ganado y de la familia en relación a la evolución de las reservas forrajeras a lo largo del año y a los ciclos de la agricultura. 


\section{perifèria}

Número 7, Diciembre 2007

www.periferia.name

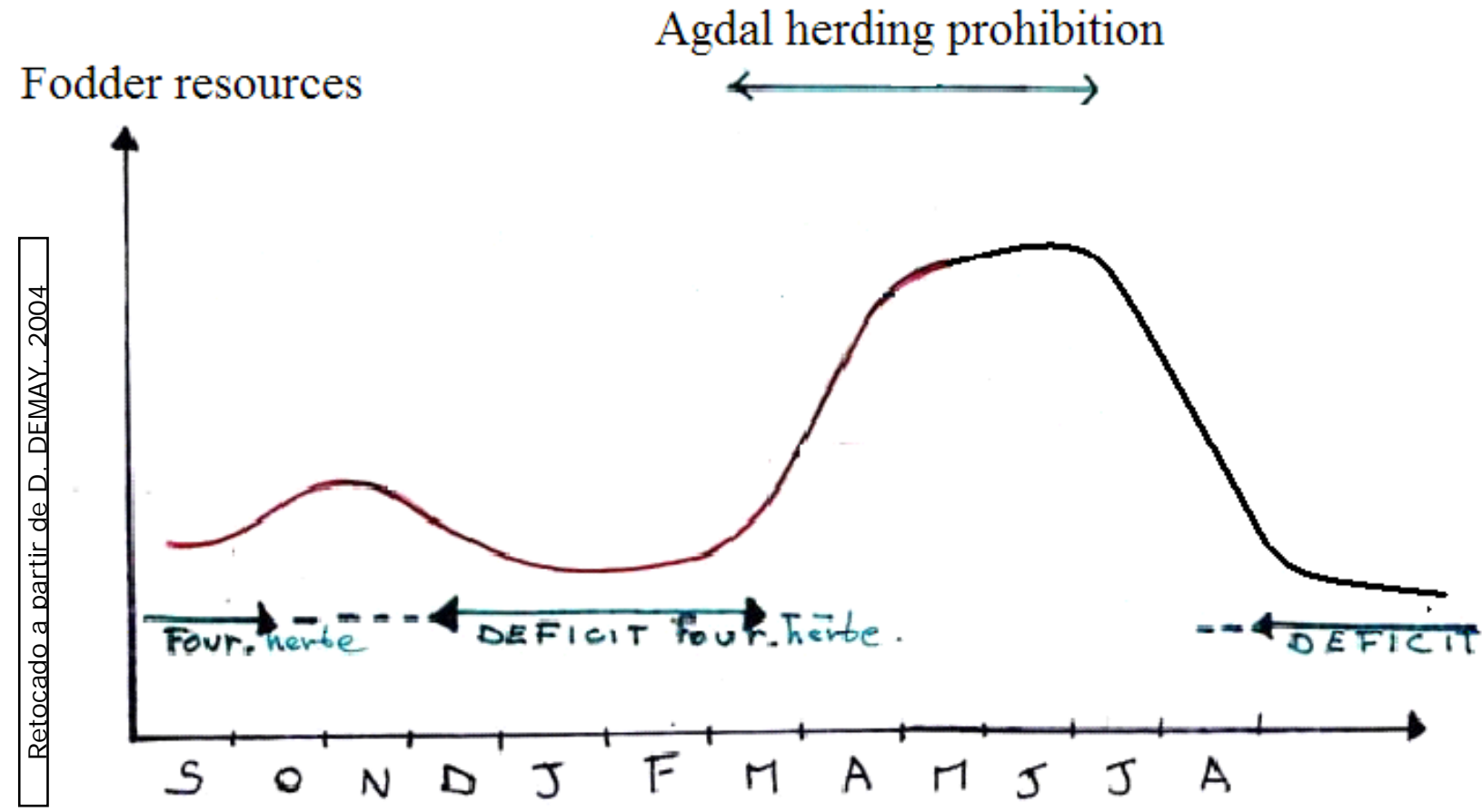

fodder disponibility on herbaceous plants with the agdal herding prohibition

Figura 3: Evolución de los recursos herbáceos en relación con la prohibición pastoral del agdal

Este esquema (Figura 3) pone en evidencia el corto período vegetativo del estrato herbáceo en primavera. La entrada de los animales al interior del espacio sometido a agdal, frenaría el potencial de crecimiento y reproducción de las plantas obteniéndose una producción menor de recursos herbáceos. También, para paliar la falta de recursos al final del verano, estos agropastores han elegido poner en agdal (prohibir al pastoreo) el territorio colectivo en primavera, pues la sequía del verano permitirá conservar los excedentes de forrajes en seco sobre el pie de la planta que habrán sido producidos durante el período de agdal, y que serán pastados (y una pequeña parte segados) a partir de la finalización de la prohibición y la apertura del territorio (entre el 15 de junio y el 10 de julio dependiendo del nivel de lluvias de cada año); se trata pues de una transferencia de forraje en el tiempo. También me han informado de que el pastoreo en los bosques ofrece un recurso forrajero de valor mediocre pero disponible todo el año: sobretodo en invierno 


\section{perifèria}

Número 7, Diciembre 2007

www. periferia. name

(mayoritariamente hojas de Encina-Carrasca) cuando los recursos en gramíneas vivaces y anuales son más bajos. Por esta razón el territorio de Ikiss (de menor altitud) se queda abierto todo el período invernal. Así pues, se llevan a menudo a los animales hacia las zonas boscosas, el cual juega un rol esencial en la alimentación del rebaño durante las épocas menos propicias.

Al mismo tiempo conviene interesarse por el ciclo de desarrollo de las gramíneas con el fin de comprender la elección de fechas de cierre (agdal/tagdalt) de los diferentes espacios. En la figura 3 observamos como después del período de "hibernación" vegetal, las reservas glucídicas están en su nivel más bajo. El relanzamiento del crecimiento de las gramíneas se hace a partir de sus reserva (a nivel los entre-nudos y de las raíces), que migran hacia los meristémas de las plantas y permiten la aparición de tallos y hojas. Esta etapa se alcanza cuando las substancias orgánicas elaboradas sobrepasan las necesidades metabólicas (sobretodo en primavera). Así pues, el período de la prohibición del agdal, se trata de una etapa crucial en el ciclo de renovación de las gramíneas y se entiende que el pastoreo de abril a mayo sería nefasto para estas especies vegetales. Esta es la razón por la cuál Warzazt se cierra un mes, del 20 de abril al 15 de mayo aproximadamente. Se trata de favorecer el recrecimiento y la reconstitución de las reservas glucídicas de estos vegetales, para así asegurar su consumo, al menos después de su período vegetativo más intenso.

Esta gestión de los territorios conduce a los habitantes de Ikiss (pueblo de origen) a desdoblar su hábitat varias veces a lo largo del año, con el fin de optimizar los recursos según las diferentes disponibilidades en el tiempo y el espacio. El calendario agro-pastoral determina el sistema de cierre y apertura (agdal) de los distintos espacios. El sistema de tagdalts implica un modo de existencia móvil, "eternamente" trashumante, y una forma particular de vivir el territorio. Se puede así subrayar el vacío humano de los espacios de altitud sometidos a la prohibición del pastoreo a nivel del "gran agdal del Yagur" y los momentos de fuerte colectivismo con la apertura de los diferentes tagdalts, poniendo en relación las actividades ligadas al pastoreo en las altas tierras del Yagur y la recogida de las nueces en poblado más bajo de Ikiss. Es así que el ciclo del agdal/tagdalts se impone en el calendario social y económico de los Aït Ikiss. 


\section{perifèria}

Número 7, Diciembre 2007

www.periferia. name

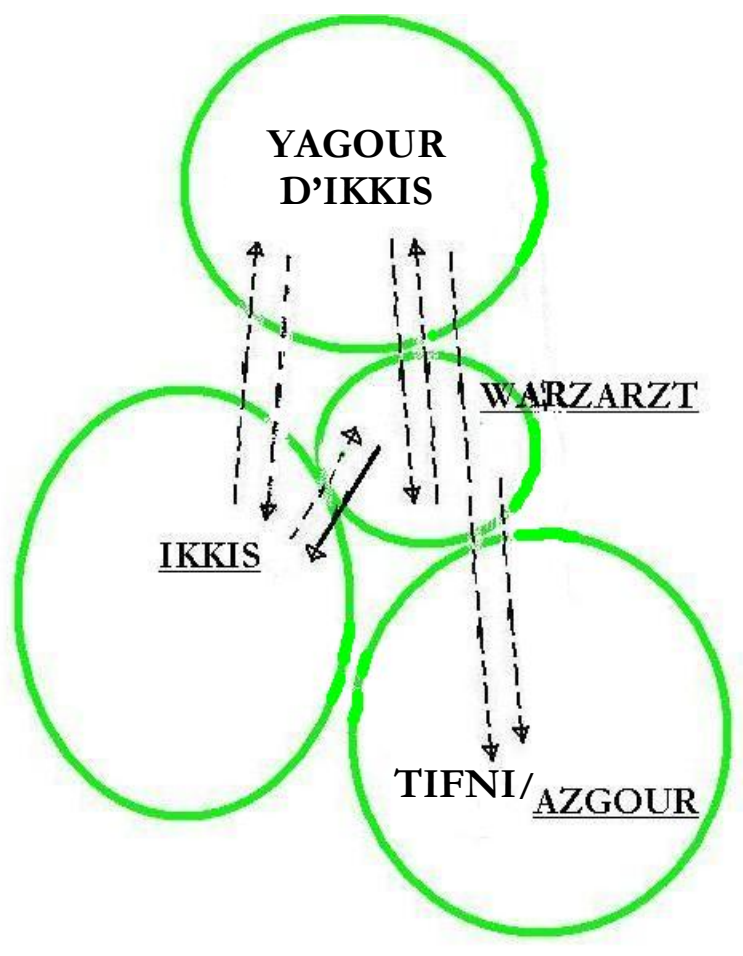

Todos los espacios están abiertos a principios de otoño y los movimientos son múltiples pero sobretodo es la recogida de la nuez (28 septiembre) que comanda los movimientos (el desplazamiento principal está siempre señalado con una flecha continua). La mayor parte de la comunidad parte a I kiss ya que allí se encuentra la mayor parte de los nogales, pero también porque es un hábitat menos alto y menos frío, y porque es el pueblo de origen de todo el grupo, el cual dispone de las viviendas más numerosas y mejor aisladas para el invierno.

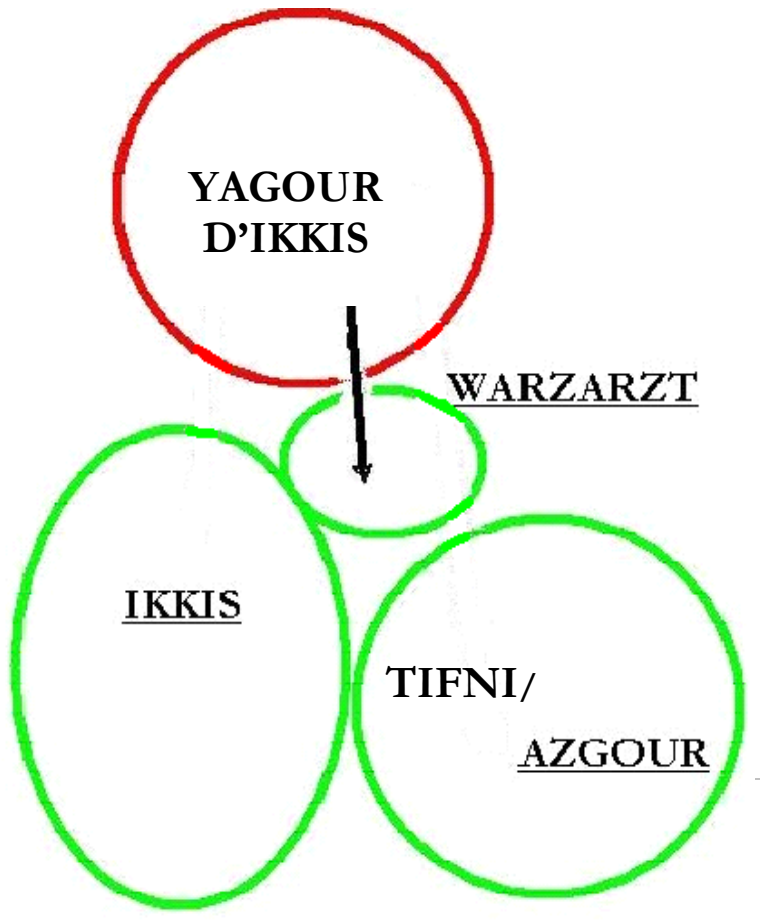

A partir del 28 de marzo, el conjunto del Yagur se somete a la prohibición del agdal durante 3 meses, para dejar crecer la hierba. Cien o doscientas personas de toda la tribu Mesioua, mayoritariamente hombres pastores que utilizan el Yagur, deben salir y retornar a sus pueblos de origen. Los Aït Ikiss, que utilizan una parte del Yagur (llamada en la figura Yagur de 


\section{perifèria}

Número 7, Diciembre 2007

www. periferia. name

I kiss pero que corresponde con la denominación Assagoul de la Figura 2), no pueden tener tampoco su ganado en su parte del Yagur. Todos los pastores están obligados a descender hacia tierras más bajas y el Yagur se queda por lo tanto vacío durante tres meses. 15 Mayo (aproximadamente)
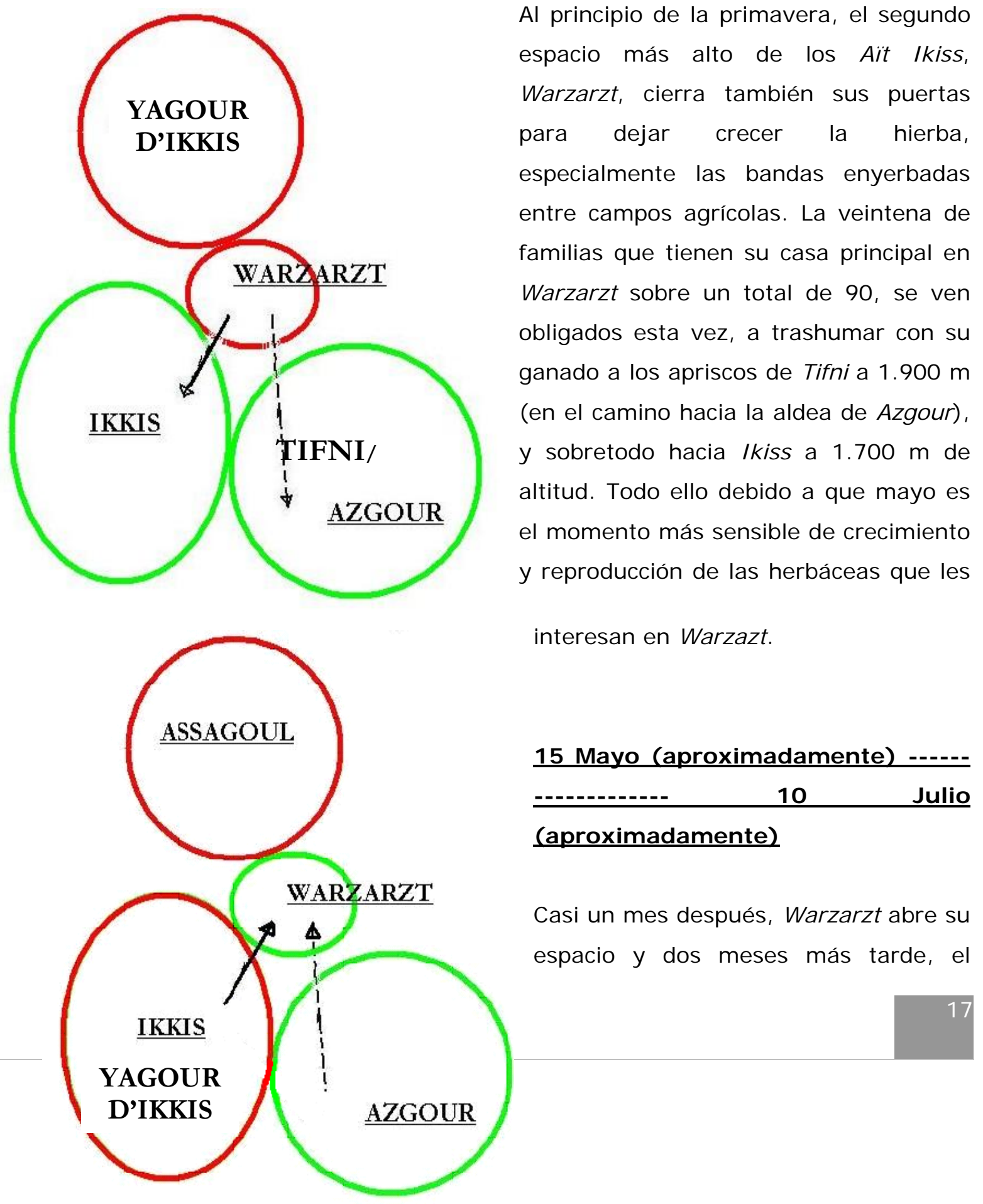

Al principio de la primavera, el segundo espacio más alto de los Aït Ikiss, Warzarzt, cierra también sus puertas para dejar crecer la hierba, especialmente las bandas enyerbadas entre campos agrícolas. La veintena de familias que tienen su casa principal en Warzarzt sobre un total de 90 , se ven obligados esta vez, a trashumar con su ganado a los apriscos de Tifni a $1.900 \mathrm{~m}$ (en el camino hacia la aldea de Azgour), y sobretodo hacia Ikiss a $1.700 \mathrm{~m}$ de el momento más sensible de crecimiento y reproducción de las herbáceas que les interesan en Warzazt. altitud. Todo ello debido a que mayo es 


\section{perifèria}

Número 7, Diciembre 2007

www. periferia. name

espacio de Ikiss, al contrario que Warzazt, se pone en agdal. Esto produce una migración inversa, las gentes suben de Ikiss hacia Warzarzt. Las tres tiendas de Warzarzt que estaban cerradas desde septiembre vuelven a abrir y el imam se desplaza con el resto del grupo a Warzazt. Este desplazamiento hacia las tierras altas parece simbolizar el comienzo del verano para los Ait Ikiss. Celebran en ese momento un maarouf (sacrificio de animales y comida ritual) con el espíritu de obtener la bendición de Alá, para un buen año sobre los pastos, gracias a la intercesión del espíritu de la santa enterrada en el poblado.

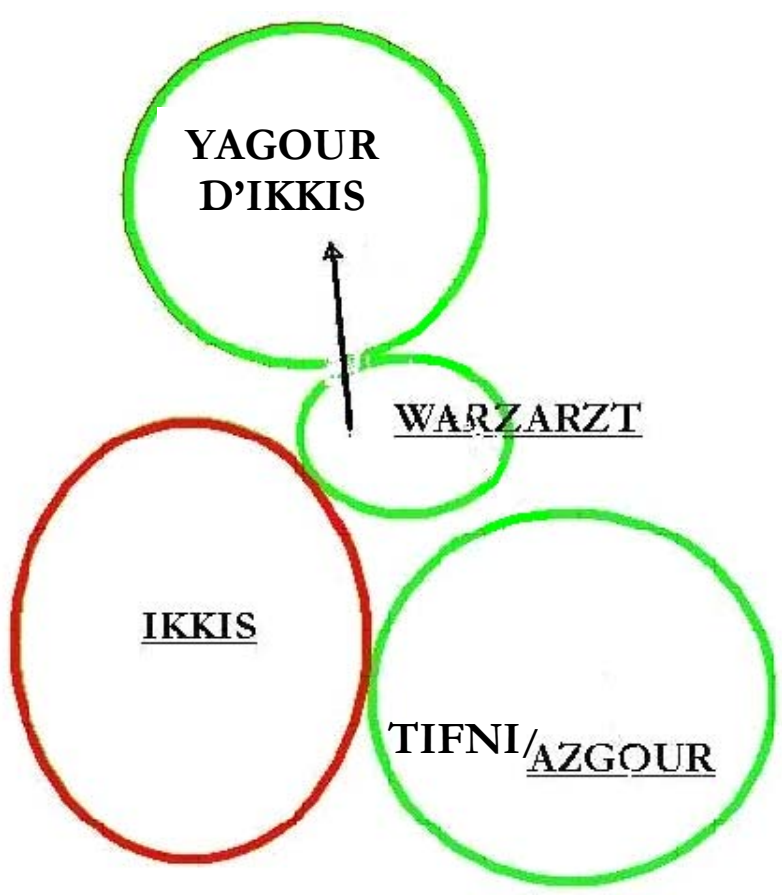

En esta época, la gran apertura del Yagur, acordada generalmente por todo el grupo Mesioua de la montaña en asamblea, da comienzo a la trashumancia de los Aït I kiss y de otros provenientes de todos los territorios contiguos de la región del Yagur, remontan las vertientes que conducen a los ricos pastos de verano. La apertura del agdal del Yagur es un evento de alta importancia local porque es un gran sitio de reunión de los animales, pero también de los seres humanos durante una buena

parte del año... Otros maaroufs y eventos festivos o rituales tienen lugar también en esta época.

Estos últimos años se asiste a ciertos cambios que afectan el sistema de los tagdalts. Por ejemplo, se suceden ciclos de sobre pastoreo en el espacio del Yagur de I kiss que en años de sequía, fuerzan la apertura prematura de sus propios tagdalts. Esto también puede debilitar el respeto hacia el gran agdal del Yagur, o 


\section{perifèria}

Número 7, Diciembre 2007

www. periferia.name

incluso la utilización de los pastos de sus vecinos... Así, fuertes tensiones nacen, especialmente entre los más ricos y el reste de la comunidad, que tienen todos dificultades para responder a las necesidades de alimentarias de sus animales al final de la estación estival. Las tensiones y discusiones alrededor de las reglas de acceso a los recursos renovables pueden tener consecuencias directas sobre el potencial de la producción agronómica del sistema de los tagdalts (de árboles frutales, de productos hortícola, de cereales, de segado de forraje para el invierno, de pastos, de bosque, etc.).

\section{Las transformaciones religiosas y el ecosistema}

Como señalaba al principio de mi texto, la hipótesis principal que intento defender es que existe una relación entre unas ciertas transformaciones religiosas y el estado actual de los ecosistemas de esta región del Alto Atlas marroquí. La hipótesis se fundamenta en la observación de un proceso interconectado de transformación de la cultura tradicional y de los pastos de verano del Yagur. El abandono de la antigua fecha de apertura de los pastos (ahora el Yagur puede abrir hasta un mes o mes y medio antes que antiguamente) y la aceleración vertiginosa del crecimiento de las superficies puestas en cultivo en el Yagur (entorno a $200 \%$ en 20 años), coinciden en el tiempo con cambios acaecidos en la cultura tradicional, concretamente en la religiosidad del agdal. Una cierta mutación cultural o un relajamiento de las tradiciones morabíticas de los santos en esta parte del Yagur, parecen constituir uno de los pasos previos necesarios para que se desarrolle la actual evolución del agdal, estando el simbolismo religioso del agdal muy relacionado con los usos del territorio.

Evidentemente todos estos cambios no son inducidos por una sola causa, sino que están ligados a un sistema complejo de elementos: crecimiento demográfico, cambio climático, aumento de la frecuencia de las sequías, participación del Estado, transformaciones de las estructuras socio-políticas, integración creciente en la economía de mercado, o emergencia de las nuevas formas de actividades como el turismo. Pero la transformación del sistema agdal también parece estar inducida por los cambios en las representaciones culturales y las instituciones religiosas tradicionales, que, sometida a la creciente presión de la mundialización cultural, se 


\section{perifèria}

Número 7, Diciembre 2007

www.periferia. name

transforman en beneficio de una filosofía extranjera al valle. Estos cambios ideológicos se imponen a través de numerosos actores de fuera de la región (imanes, televisión, radio, voluntarios religiosos, funcionarios, profesores, etc.). Estos actores son quienes traen principalmente las ideas y saberes enseñados en la ciudad, conjuntamente con la influencia de los jóvenes de la propia sociedad local que consiguen estudiar o trabajar en las aglomeraciones urbanas $u$ otros núcleos del exterior.

La razón por la que defiendo que la disminución de creencias y prácticas religiosas influye en la transformación de la regla del agdal y de la utilización de los pastos, es porque una parte de los agropastores me lo han hecho entender así. Aunque hoy parecen haber perdido mucho peso, he recogido descripciones de algunas de las antiguas creencias que protegían la regla del agdal. Por ejemplo, un hombre vestido de blanco sobre su caballo blanco que aparece cada año, a partir de la prohibición de pastorear en el Yagur, para salvaguardar el agdal de los "ladrones" deshonestos castigándoles de diferentes maneras. O esa de los 360 santos que circulan juntos para asegurar la vigilancia del Yagur con sus caballos y sus camellos, símbolos de las grandes caravanas del desierto, de largos viajes y por lo tanto de devoción y respeto. Desde hace más de 20 o 30 años, este tipo de leyendas sirven cada vez más a la burla que al respeto de la regla, pero eran, y siguen siendo para algunos pocos, un elemento de respeto hacia el agdal. Un ejemplo de esas pocas personas, se observa en algunos usos (sin mucho éxito) de esta antigua cultura de lo sobrenatural, para intentar oponer resistencia a los cambios citados. Así, hay informantes que me han transmitido sus sentimientos de culpabilidad o su miedo frente a los cambios acaecidos en las últimas décadas difundiendo frente a sus paisanos que trabajamos y trabajamos los cultivos, ipero casi no obtenemos grano! Los diablos se encargan de castigar a esos que cultivan privadamente las tierras del Yagur de Ikiss $^{2}$ (antaño únicamente de uso pastoral y colectivo) a través del robo de granos sobre la planta viva para dárselos después a los linajes santos del Sur que tratan mejor a sus santos patrones. De estas frases

\footnotetext{
2 Zona dónde la puesta en cultivo de los pastos colectivos está siendo especialmente intensa. Se estima aproximadamente, que $70 \%$ de las praderas más ricas han sido transformadas en tierras agrícolas en a penas veinte años, es decir, 32 hectáreas de un total de unas 500 hectáreas del Yagur de I kiss (DEMAY 2004: 60).
} 


\section{perifèria}

Número 7, Diciembre 2007

\section{www.periferia.name}

se podría deducir que los pastores atribuyen el castigo al mismo tiempo al cultivo de los pastos del Yagur y a la disminución de la fe hacia los santos. No hay duda de que uno de los objetivos de estas referencias al mundo sobrenatural, del que ya hemos hablado y que eran mucho más presentes antaño, es el garantizar la continuidad del sistema agdal como institución protectora de los ecosistemas pastorales que son una de las bases principales de la economía local.

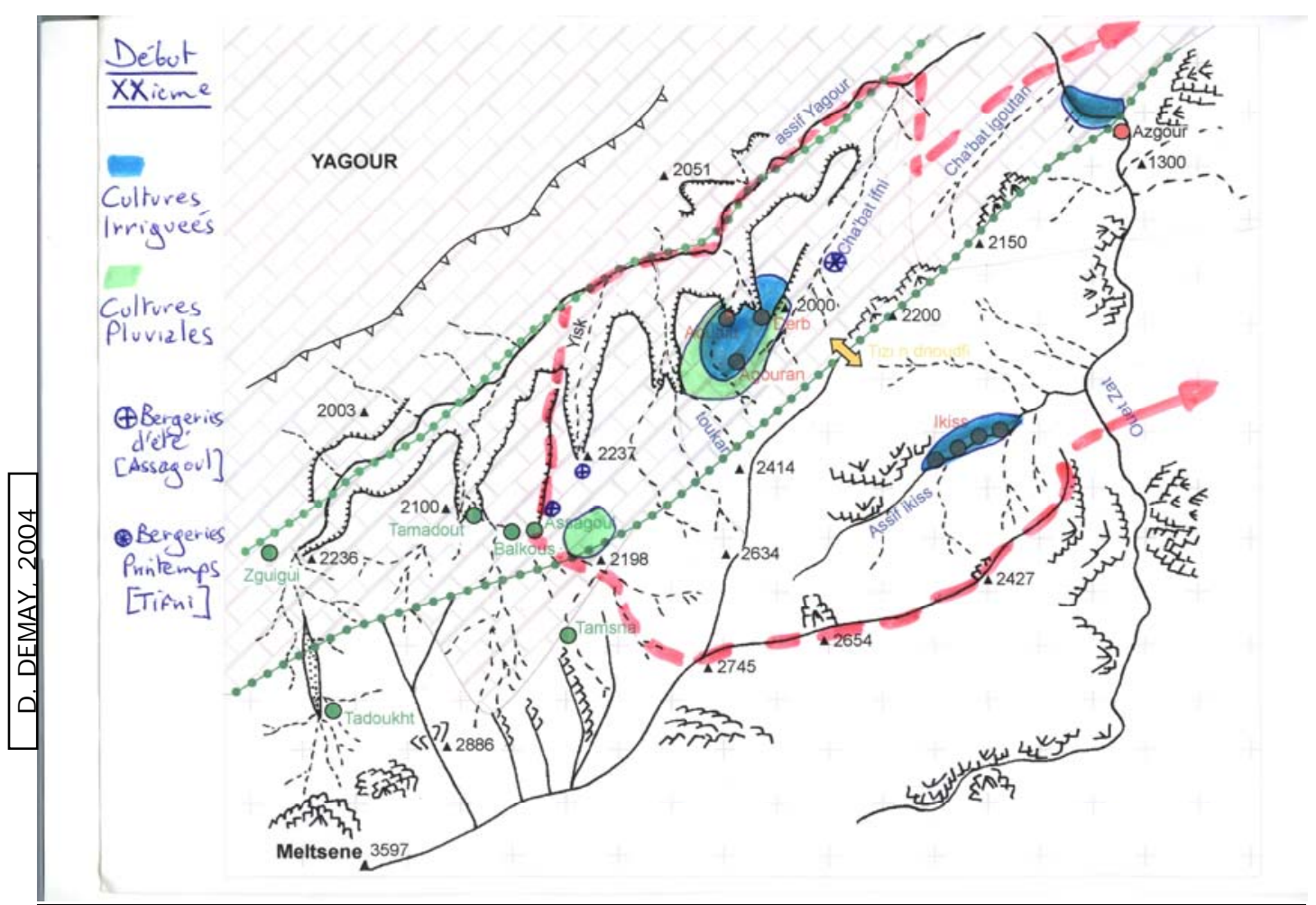

Mapa 3: Situación de la puesta en cultivo del Yagur de Ikiss a principios de siglo XX. 


\section{perifèria}

Número 7, Diciembre 2007

\section{www.periferia.name}

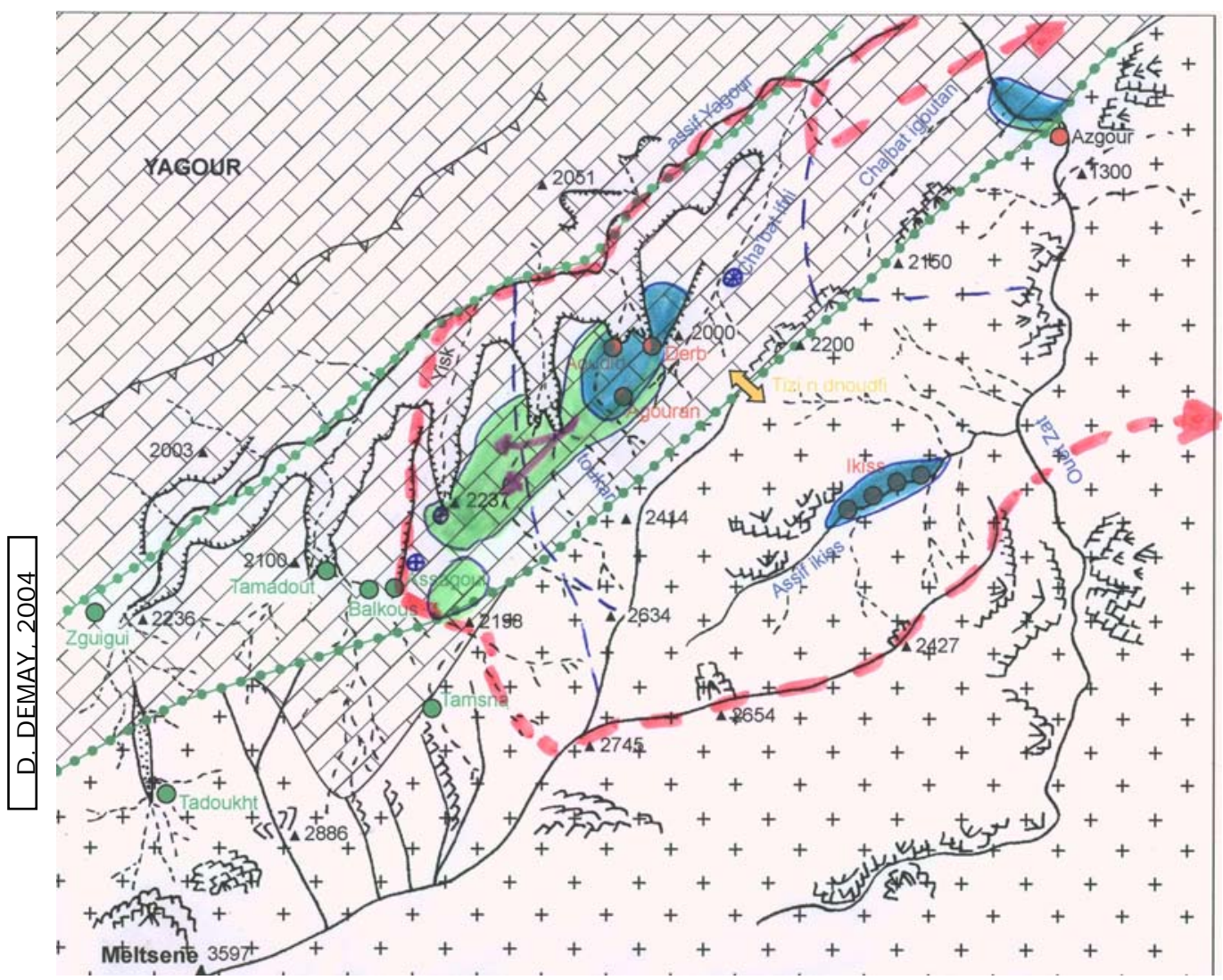

Mapa 4: Situación de expansión de los cultivos del Yagur de I kiss a partir de los años 80.

\section{Conclusiones}

En respuesta a mi pregunta inicial, considero que las transformaciones religiosas descritas, constituyen efectivamente un elemento determinante en la nueva estructuración de la economía y ecología locales. El Islam morabítico con su epicentro en los santos, apoya el régimen de gestión común que constituye el agdal del Yagur, y con sus diversas opciones institucionales y reglamentarias del acceso a los recursos silvo-pastorales corresponde a una vía de protección de la biodiversidad y del medio tradicionales. Hasta que los cambios religiosos no se materializaron en los años 70-80, dichos pastos estaban mayoritariamente explotados comunitariamente y protegidos simbólicamente por un linaje santo del Atlas. Coincidiendo con la época del inicio de los cambios religiosos, una parte de estos pastos se está convirtiendo en un territorio fragmentado en pequeñas parcelas privadas. Así, los ecosistemas herbáceos se transforman de un espacio 


\section{perifèria}

Número 7, Diciembre 2007

www. periferia.name

pastoral de propiedad colectiva, a un ecosistema de monocultivo gestionado privadamente por los individuos o sus familias. Al mismo tiempo, la prohibición de pastorear del agdal se respeta cada vez menos, y de hecho la antigua fecha de apertura de los pastos ha sido abandonada.

Sea como sea, es un hecho que en el enfoque dominante de los proyectos de conservación medioambiental y desarrollo socio-económico, y esta podría ser mi conclusión más trascendente, encuentro una importante tendencia a atenuar la importancia de la dimensión cultural y espiritual de las poblaciones objeto de dichos proyectos, especialmente cuando se trata de prácticas religiosas no mayoritarias o marginadas, mientras en este ejemplo se prueba de gran importancia. Concretamente, en el caso de Marruecos, los sistemas religiosos populares, urbanos o rurales, son sometidos a una presión social y moral fuerte que los fragiliza, en parte apoyado por el auge de un Islam más ortodoxo y en parte apoyado por unas crecientes burguesía y clase media, que intentan imponer su criterio religioso sobre el de las prácticas populares aquí descritas. Los discursos y las concepciones dominantes degradan muy a menudo estas prácticas religiosas, percibidas como arcaicas y poco ortodoxas desde el punto de vista de cierto Islam. Como ya lo hemos dicho, esta actitud debilita el sistema agdal que parece haber probado, a través de los siglos, ciertos resultados positivos en materia de durabilidad bioecológica (Kerautret 2005: 150, Al Ifriqui 2005: 35, Alaoui Haroni, Al Ifriqui \& Simonneaux 2005, Alaoui Haroni \& Al ifriqui 2006, Ballini C., Bertaudière-Montès, Deschamps-Cottin, Lempérière \& Montès 2005: 15), social (Auclair \& Alifiqui 2005: 17) y económica (Dominguez 2004: 165, Dominguez, Bourbouze, Demay \& Genin 2007).

\section{Bibliografía}

Al Ifriqui M., 2005 - Les pelouses humides du Haut Atlas de Marrakech (Oukaïmeden et Aït Mizane). Intérêt écologique de la gestion « agdal », Rapport de recherche, Programme AGDAL, Marrakech, $35 \mathrm{p}$.

Alaoui Haroni S., Al Ifriqui M. \& Simonneaux V. 2005 - Impact de l'action anthropique sur les pâturages humides du Haut Atlas occidental (le cas de la haute vallée des Aït Mizane), Poster. 2ème Congrès Méditerranéen, Ressources en eau dans le Bassin méditerranéen, Watmed 2, 14-17 nov., Marrakech, Maroc.

Alaoui Haroni S. \& Alifriqui M., 2006 - Cartographie et dynamique de la végétation 


\section{perifèria}

Número 7, Diciembre 2007

\section{www.periferia.name}

des zones humides du Haut Atlas, Poster, Premières doctoriales du LPED, Marseille, 16-17 juin

Auclair L., 2003 - Mémoire du Projet de recherche « Les agdal du Haut Atlas marocain : Biodiversité et gestion communautaire de l'accès aux espaces sylvopastoraux», Laboratoire Population Environnement Développement, IRD, Marseille, $20 \mathrm{p}$.

Auclair L. \& Alifiqui M., 2005 - Les agdal du Haut Atlas marocain, enjeux d'une recherche pluridisciplinaire, In Actes des $2^{\text {èmes }}$ Rencontres d'Anthropologie du Maghreb, Centre J acques Berque, éd., sous presse, Rabat, $17 \mathrm{p}$.

Auclair L., 2006 - Rapport final, partie V, Programme AGDAL, Marseille, 18 p.

Ballini C., Bertaudière-Montès V., Deschamps-Cottin M., Lempérière F. \& Montès N., 2005 - Conséquences écologiques des "agdal" forestiers : contribution au maintien de la biodiversité végétale et animale. Le cas de la vallée des Aït Bouguemez (Haut Atlas central, Province d'Azilal), Rapport de recherche, Programme AGDAL, Marseille, $15 \mathrm{p}$.

Bellaoui A., 1989 - Les pays de l'Adrar-n-Dern. Etude géographique du Haut Atlas de Marrakech, Thèse de Doctorat, Université de Tours (MRK), 505 p.

Bourbouze A., 1981 - L'élevage dans la montagne marocaine: organisation de l'espace et l'utilisation des parcours par les éleveurs du Haut Atlas, Thèse, INA, Paris-Grignon et IAV, Rabat, 323 p. + annexes.

Brinet J., 2006 - Mutations pastorales et gestion des ressources pastorales dans le bassin d'Imlil (Haut Atlas de Marrakech, Maroc), Mémoire de Master 2 « Sciences géographiques », sous la direction de Elisabeth Dorier-Apprill et Laurent Auclair, Université de Provence, Aix-Marseille I, $169 \mathrm{p}+$ annexes. Mention B. Programme AGDAL.

Demay S., 2004 - Diagnostic agraire dans le Haut Atlas marocain. Territoire des Aït I kiss, Mémoire de DAA, spécialité SES, INA Paris-Grignon, Programme AGDAL, $60 \mathrm{p}$ + annexes.

Descola P., 1986, La nature domestique : symbolisme et praxis dans l'écologie des Achuar, Ed. MSH, Paris, 450 p.

Dominguez P., 2004 - Occupation de l'espace et usages des ressources naturelles chez les agro-pasteurs berbères du Haut Atlas marocain : le cas des agdal dans le haut plateau de Yagour, Mémoire de DEA « Anthropologie sociale et ethnologie », EHESS Paris, sous la direction de A-M. Brisebarre, Programme AGDAL, 165 p.

Dominguez P. \& Bourbouze A., 2006 - Agdal du Yagour, Rapport de recherche, Programme AGDAL, Marseille, $53 \mathrm{p}$.

Dominguez P., Bourbouze A., Demay S. \& Genin D., 2007 - Un exemple de production pastorale du système agdal dans l'Atlas de Marrakech, Le Yagour, Actes du colloque AGDAL, Séance 4, 25 p.

Gellner E., 1969 - Saints of the Atlas, Ed. Weidenfield and Nicholson, London, 299 p. 


\section{perifèria}

Número 7, Diciembre 2007

\section{www.periferia.name}

Genin D. (compilation et synthèse), 2006 - Les agdals des Aït Bouguemez (Haut Atlas central). Fonctionnement, impacts écologiques et mutations d'un système traditionnel de gestion des ressources pastorales et forestières, Rapport de recherche, Programme AGDAL, Marseille, $63 \mathrm{p}$.

Hoarau B., 2005 - Tourisme interculturel et développement local, Master I « Sciences de l'Homme et de la Société », Mention Anthropologie, Université de Nice - Sophia Antipolis, Nice, 73 p.

Harris M., 1978 - El desarrollo de la teoría antropológica. Una historia de las teorías de la cultura, Ed. Siglo XXI, Madrid.

Hammoudi A. 1988 - La Victime et ses masques : essai sur le sacrifice et la mascarade au Maghreb, Ed. du Seuil, Paris, 251 p.

Ingold T., 1992 - «Culture and the Perception of the Environment » in E. Croll and D. Parkin Bush base: forest farm. Culture, environment and development, Ed. Routledge, London, 39-56 pp.

Kerautret L., 2005 - Entre Agdal et Moucharika, Mémoire de Maîtrise « Environnement et société », Université de Provence, Programme AGDAL, 150 p.

Latour B., 2004 - Politics of nature, Ed. Harvard University Press, Cambridge, Massachusetts, p. 307.

Mahdi M., 1999 - Pasteurs de l'Atlas. Production pastorale, droit et rituel, Ed. Fond. Adenauer, Casablanca, 347 p.

Montagne R., 1930 - Les berbères et le Makhzen dans le sud du Maroc, Félix Alcan, Paris.

Odum E. P., 1959 - Fundamentals of ecology, Ed. Saunders, Philadelphia, 546 p.

Posey D. A. \& Balee W., 1989 - Resource Management in Amazonia: indigenous and folk strategies, The New York botanical garden, Bronx (N. Y.).

Rachik H. 1992 - Le sultan des autres, rituel et politique dans le Haut Atlas, Ed. AFRIQUE-ORIENT, Casablanca, 175 p.

Sellier E. 2004 - L'agdal du Yagour. Territorialités au pluriel pour la protection de la nature dans le Haut Atlas de Marrakech, Maîtrise de géographie sous la direction de E. Dorier-Apprill. Université de Provence, Institut de géographie et d'Aménagement, Aix-Marseille I, Programme AGDAL, 164 p.

Simenel R., 2001 - A l'ombre des arganiers, la société des montagnards chleuh : appropiation pratique et symbolique d'un arbre dans l'Anti-Atlas occidental marocain, rapport de DEA d'anthropologie sociale (projet de thèse), Université de Paris X, Nanterre, $36 \mathrm{p}$.

Simenel R., 2004 - «De la forêt du saint au pâturage des chrétiens (Perception du paysage et gestion du couvert végétal chez les Aït Baarmran du Sud Marocain) » in Cahiers de recherche du CJ B, Rabat, I, 119-133 pp.

Steward J. H., 1973 (1955) - Theory of culture change: The methodology of multilinear evolution, Ed. University of Illinois Press, Illinois, 244 p. 


\section{perifèria}

Número 7, Diciembre 2007

www. periferia. name

Strathern M. (dir), 1980 - Nature, Culture and Gender, Ed. Cambridge UP, Cambridge, 174-222 pp. 